\section{Walkscapes. El andar como práctica estética}

Land \& Scape Series

Francesco Careri

208 pásinas, $15 \times 21 \mathrm{~cm}$, duetono

Editorial Gustavo Gili S.A.

Barcelona, 2002

Texto: español, inglés

Errar humanum est. En pleno revival de los situacionistas (Debord y Perec mediante) $\mathrm{y}$ en medio de un acelerado proceso de transformación de las ciudades, donde cad vez es más borroso el límite entre centro y periferia, Gili publica el primer volumen de esta serie que presenta otra mirada (más) respecto al problema del andar y su relaciones con la producción en el campo del arte, el urbanismo y la arquitectura.

Tal vez la diferencia entre este texto y otros de su tipo radique en el esfuerzo del autor por construir una continuidad entre los diferentes personajes y movimientos que han tomado el problema del recorrido como un modo de conocimiento de la realidad: Desde los primeros nómades hasta el grupo Stalker, pasando por Benjamin, los surrealistas, el Dada y Richard Long.

Para los aficionados a las derivas, paisajistas inclinados al land-art y arquitectos investigadores, el libro puede aportar un panorama completo y nuevos datos: se han incluido completas bibliografías por capítulo y un trabajo de recopilación gráfica que permite ver en la misma edición fotografías de los senderos neolíticos de Somerset y registros de los Free Flux- Tours de los Fluxus en Nueva York.

\section{Espacio, Devenir y el Rescate del Tiempo}

En el contexto evaluado de 500 años de ciencia física

Jaime Garretón

blanco y negro

Ediciones ChileAmérica - CESOC

Santiaso de Chile, 2002

Texto: español

Nadie parece saber qué se ha hecho el tiempo. Como dice Rafael Sánchez Ferlosio: "Si ya pasara el futuro de una vez, empezaríamos tener tiempo de hacer algunas cosas". Con espacio está pasando algo parecido: tambié se nos desdibuja constantemente. El libro de arquitecto Jaime Garretón, presentado en última Bienal de Arquitectura de Santiago, trata de entregar guías para esta discusión. Desde un punto de vista que combina la ciencia física, la filosofía y el análisis de la percepción, el autor propone un recorrido a través de la evolución de la ciencia a lo largo de los últimos 500 años: la revolución heliocéntrica, Descartes, Darwin y el progreso, o la relatividad. Este recorrido esboza un panorama que retrata la enorme influencia que el desarrollo de la física pura ha tenido en la cultura y en nuestra visión del mundo actual, particularmente en lo referido a la problemática del espacio. El volumen está compuesto por bloques de relativa autonomía que permiten diferentes lecturas de acuerdo al interés del lector y que facilitan la entrada al denso conjunto de ideas expuesto.
338 páginas $15,3 \times 22,8 \mathrm{~cm}$

\section{Nuevo DISEÑO N 3}

Revista The Architectural Review N ${ }^{\circ} 1267$

Small Wonders

98 pásinas, $23 \times 30 \mathrm{~cm}$, color Bimestral

Ediciones Nuevo DISEÑO S.A.

Santiago de Chile

Agosto - septiembre de 2002

Texto: español

Esta tercera entrega incluye (como de costumbre) una extensa agenda que recomienda y selecciona objetos, libros, exposiciones y restaurantes de Santiago. Tal como el nombre de la publicación lo indica, sus contenidos son presentados a través de una mirada ecléctica que abarca diferentes áreas del interiorismo, el diseño gráfico, el arte y la arquitectura: la última Bienal de Sao Paulo, nuevas tendencias en lo que a portadas de revistas se refiere, el trabajo de los arquitectos Sebastián Gray y Tania Concko, las recientes exposiciones de la Galería Animal (Cienfuegos y Marín) y las fantasías de un grupo de decoradores en el piso 14 del hotel Carrera.

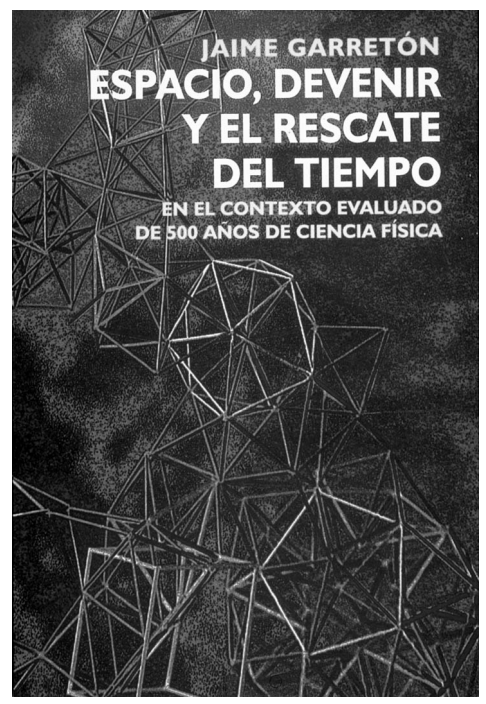

98 pásinas, $23 \times 29,5 \mathrm{~cm}$, color

mensual

Londres, Inglaterra.

Texto: inglés

Size does matter. Esta edición de AR podrí considerarse como otra contribución a la discusión arquitectura $v / s \quad m 2$. QQué formatos resiste la obra de arquitectura? El interés por lo pequeño, que plantea ciertas ideas de lo funcional, lo manejable y lo económico, remite hoy a unas cualidades materiales y constructivas que aparecen más evidentemente en las obras de menor tamaño, y que las relacionan con ciertas experiencias táctiles. Más allá de la excentricidad y las limitaciones que este formato plantea, ante una realidad consumida por los delirios de grandeza y las multinacionales globales, lo pequeño podría identificarse con lo local, autogestionado y autoconstruido. AR presenta una selección de proyectos que incluye cabinas para veraneantes en España, un ático en Alemania, un baño público en Croacia y un centro comunitario en India. Ante cierta cuota de ingenuidad, modestia y economía que plantean estos trabajos, volvemos a la reflexión por la arquitectura como un vestido para el cuerpo.
EMAP Communication
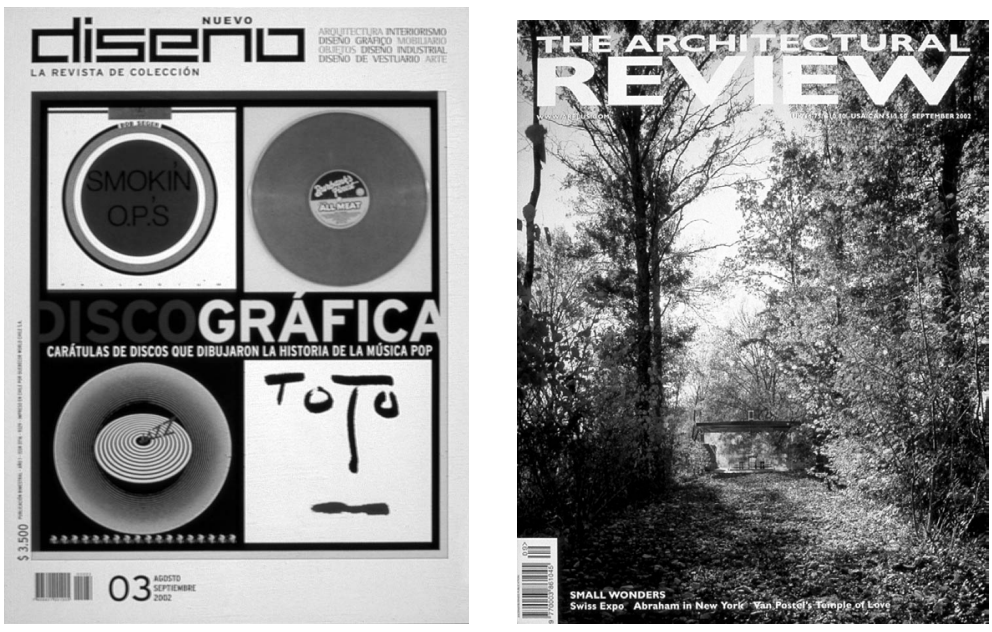

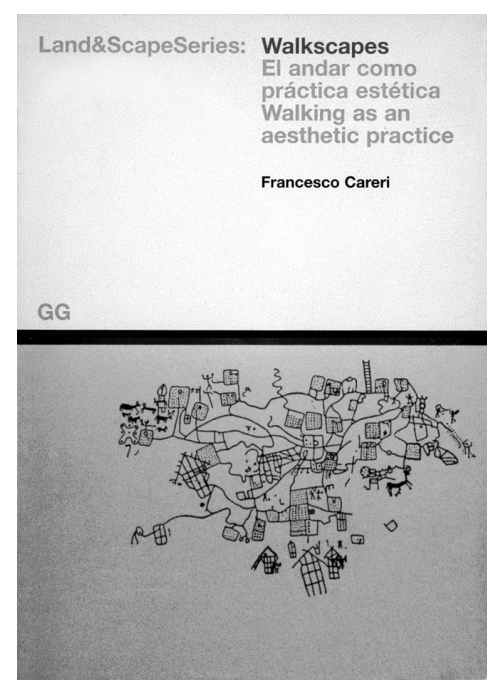

